\title{
Editorial
}

\section{Music education in a time of austerity}

We have discussed in these editorials before the broad range of interests that music education encompasses (Fautley and Murphy, 2015a). The range that we described therein is a strength of our discipline. We are, however, now living in troubling times, and the global downturn in the economy is having effects in all sorts of ways on many aspects of our lives, both personal and professional. Music education is not immune from these changes. We are living through a time of austerity, and in many jurisdictions, the refrain has been 'we're all in this together' as a way of explaining away government decisions or unpopular economic strategies. But are we? It is in times of austerity that we often feel that we need to make the case for music education even louder than we have done before. Yet herein lies one of our problems. Many music educators feel in these times of austerity that music education is under threat, and that the proper course of action under such circumstances to take is to increase activities related to advocacy. This is problematic in a number of ways, as we shall now discuss.

One of the main issues with advocacy is that of viewing and treating it as being part of a solution. We have discussed advocacy before in these editorials (Fautley and Murphy, 2015b), and we feel it is worth returning to consider some of the ways in which this may not always be working in the best interests of all of the stakeholders. As Bowman has put it:

... it is evident that our profession equates philosophy with advocacy: a tool for rationalizing current practices and affirming their inherent dignity; the kind of thing that can be easily trotted out should adverse circumstances seem to warrant it ... (Bowman, 2005, p. 155)

And if nothing else, we are certainly living in times of 'adverse circumstance' at the moment.

Notions of advocacy, however, can all too often be predicated on promoting extrinsic values of music education, in other words the benefits that music education has on other subjects on the school curriculum, on general learning abilities, or on aspects of social skills. This is in and of itself problematic. After all, as Bowman observes elsewhere:

Intrinsic musical values are ends in themselves, whereas extrinsic values stem from music's service to nonmusical ends. However, when we divide human values into two distinct and opposing kinds, neither has much real worth: music's intrinsic values are largely divorced from the day-to-day concerns of life and living, while its extrinsic values are not really musical. These ways of thinking marginalise many of music's most powerful potentials, seriously undermining our efforts to establish the human import of music and music education. (Bowman, 2013, p. 3)

All this is well known, but what can happen in times of austerity is that there can be a real danger that music education champions and organisations default into an advocacy 
mode, but that of advocacy for their own type and flavour of music education. Thus, while the type of music education that in BJME 32,1 we labelled musical education concentrates its advocacy onto activities which involve singing and learning to play an instrument, music education proponents focus their advocacy on matters appertaining to classroom provision, and music in education voices advocate for the place of music on the school curriculum. Unreconstructed self-interest plays a part in this, certainly, but what can be a danger is that such advocacies are guilty, at best, of what our religious friends would call sins of omission, in that they neglect to include other typologies of music education. This oversight is entirely understandable when facing problems in key areas of funding. What can be slightly more sinister, however, is when omissions become what might be termed as counter-insurgency activities, and all other forms of music education are deliberately downplayed, denigrated, or dismissed.

Now, we are not saying that any of this is actually now happening, but that in these times of austerity we want to be very aware that it has the potential for happening. Not dissimilar things have happened in the past when times were hard, and it is sincerely hoped that they will not again. We know that a number of music education organisations are committed to advocacy, and devote considerable time and effort to this, but the warnings from history are there, and we need to learn from them this time round. After all, as we noted above, 'we are in this together'! As we move towards the end of recession, advocacy is likely to take on a different hue, and yet still we need to be aware of the range and scope of music education in all its fascinating differentness, and not confine ourselves to privileging the familiar. What we can be sure about is that the pages of BJME will continue to provide a platform for all voices in music education, and that the broad sweep of all its rich typologies will be represented herein.

Which takes us to the contents of this current edition. The example of Finland is often held up to the international community as a beacon of good practice; Tuulikki Laes and Patrick Schmidt provide a narrative in their article which offers a peek inside a music school for students with special educational needs. This provides a great deal of food for thought with regards to how and why music education operates in particular ways. Discussions at the intersection of policy, inclusion, and the ways in which teachers operationalise their pedagogies are key in this. We stay in Finland for the research of Esa Virkullula, but change institution, as we move to the music conservatory. In this study Virkulla investigates pedagogical perspectives associated with the development of musicianship in popular and jazz music studies, viewed through a communities of practice lens. This work invites us to reflect on the nature of teaching and learning, and of appropriateness too.

Notions of 'formal' and 'informal' in music education of all flavours is currently a matter of close attention in many quarters. In his article, Graham McPhail discusses the work of Chris Philpott. This includes an examination of conceptions of 'knowledge', and of what counts as knowledge. This is a highly pertinent argument in the current climate, and in this piece McPhail argues for a balance between pedagogy and knowledge. We have invited Chris Philpott to contribute a response to this piece, and we look forward to publishing this in BJME in the not too distant future.

We move to China for a piece by Yang Yang and Graham Welch which investigates pedagogies for teaching and learning folk music in formal educational settings. The messages from this piece have resonances around the world, where the implications of 
learning music from primarily oral traditions rub up against western classical music. We turn next to the place and role of composing in music education, which differs significantly between jurisdictions. In their article, Johanna Maria Roels and Peter Van Petegem from Belgium discuss the role that composing plays in the piano class for children. In this the children concerned compose music as a normal part of their weekly piano lessons. The article considers the role of visual images in the composing processes of these youngsters. Finally in yet another truly international content edition of BJME, we go to Spain, where Albina Cuadrado and Gabriel Rusinek present their research into singing and vocal instruction in selected Spanish educational settings. Vocal music figures as a learning and performing modality in the vast majority of international settings, so again the lessons from this study certainly have far more than the regional implications.

The breadth and scope of BJME material in this edition continues to inspire, and, following the success of our recent edition focusing on Africa, continues to place the BJME in the vanguard of commentaries on the international music education scene. We hope you find these articles interesting and informative, and thank you for your continuing readership.

MARTIN FAUTLEY and REGINA MURPHY

BJME Co-Editors

\section{References}

BOWMAN, W. (2005) More inquiring minds, more cogent questions, more provisional answers: the need to theorize music education - and its research 1. Music Education Research, 7, 2, 153-68.

BOWMAN, W. (2013) The ethical significance of music-making. Music Mark Magazine, Winter 2013-14, $3,3-6$.

FAUTLEY, M. \& MURPHY, R. (2015a) What is music education? - Editorial. British Journal of Music Education, 32, 1, 1-4.

FAUTLEY, M. \& MURPHY, R. (2015b) Difficult questions in music education? - Editorial. British Journal of Music Education, 32, 2, 119-112. 